\title{
Morphology and functional cytology of the small intestinal mucosa in malabsorptive disorders and other diseases ${ }^{1}$
}

\author{
LIONEL FRY ${ }^{2}$ AND R. M. H. MCMINN \\ From King's College Hospital, London, S.E.5, and the \\ Department of Anatomy, King's College, London, W.C.2
}

SYNOPSIS Small intestinal biopsies from 98 patients have been studied macroscopically, histologi $\frac{\overrightarrow{0}}{\omega}$ cally, and histochemically, and the results correlated with laboratory and clinical observationsiv Neither a convoluted nor a flat mucosa can be considered diagnostic for any specific disease. AO flat mucosa was found in one adult with intestinal Hodgkin's disease and in another following totaB gastrectomy.

Histochemically all specimens from subjects with coeliac disease and idiopathic steatorrhoeक्षे showed a deficiency of succinic dehydrogenase in the epithelial cells, and the histochemical test for this enzyme, although not specific, may be a useful aid to diagnosis, since the degree of deficiency in these diseases was usually grosser than that in any other conditions. Other but variable enzyme deficiencies that may be present in these two diseases showed no correlation with the reduction of succinic dehydrogenase activity, nor was there any correlation between reduced enzyme activities ands the severity or otherwise of the clinical features.

A number of specimens from patients with conditions other than coeliac disease and idiopathiç steatorrhoea that had a normal macroscopic appearance showed some reduction of intracellulas enzyme activities histochemically. This was not so in the control group, and if these deficiencies can? be confirmed biochemically, then histochemical tests may give an earlier indication of disordered function than macroscopical or routine histological examination.

At present neither the macroscopic appearance nor any single histological or histochemical test on the biopsy specimen is diagnostic for a particular disease. These findings must be considereo with the clinical details and results of other investigations in establishing a diagnosis.

The fact that there are morphological changes in the mucosa of the small intestine in primary malabsorptive disorders, i.e., idiopathic steatorrhoea, coeliac disease, and tropical sprue, is now well established (e.g. Sakula and Shiner, 1957; Butterworth and Perez-Santiago, 1958; Rubin, Brandborg, Phelps, and Taylor, 1960; Shiner and Doniach, 1960; Padykula, Strauss, Ladman, and Gardner, 1961; Padykula, 1962; Cooke, Fone, Cox, Meynell, and Gaddie, 1963; Bank, Marks, Moshal, and Timme, 1964). These changes take the form of blunting and flattening of the villi with a resultant decrease in the absorptive surface. The varying

'This work formed part of a thesis accepted by the University of London for the award of the degree of M.D. to L.F.

2Present address: Department of Dermatology, The London Hospital, degrees of change in the villous architecture haves been descriptively termed and graded by Holmes? Hourihane, and Booth (1961), and from the apo pearances seen with the dissecting microscope they have described, apart from finger-shaped and leafor shaped villi, a 'convoluted mucosa' and 'flat mucosa' $N$ the latter representing the greatest decrease in the absorptive surface. These apparent deviations fromb the normal are thought to represent the result of a 'damaging' influence on the cells of the mucosa witt subsequent unsatisfactory function of the smalis intestine.

Similar changes have been reported in conditions other than primary malabsorptive disorders, e.g. after partial gastrectomy (Doniach and Shiner 1960), in jejunal diverticulosis (Schiffer, Faloon $\bigcirc$ Chodos, and Lozner, 1962), in Crohn's disease 
(Shiner and Drury, 1962), in giardiasis (Cameron, Astley, Hallowell, Rawson, Miller, French, and Hubble, 1962), in ulcerative colitis (Salem, Truelove, and Richards, 1964), and in some cases of malignacy arising from the small intestine (Creamer, 1964; Wangel and Deller, 1965).

The fact that malabsorptive disorders may have such a varied clinical presentation (Badenoch, 1960), while subjects with similar clinical features display such varying morphological appearances of the small intestinal mucosa (Booth, Stewart, Holmes, and Brackenbury, 1962), suggests that the functional capacity of the intestinal mucosa does not necessarily correlate with its gross morphology. In this study the mucosa has been investigated macroscopically, microscopically, and histochemically to determine whether there is any correlation between the gross morphology of the gut, its functional cytology, and the clinical features.

\section{MATERIALS AND METHODS}

Biopsy specimens were obtained with the Crosby capsule (Crosby and Kugler, 1957) from 98 subjects. The specimens were taken from the duodenum or upper jejunum, and the patients classified into six groups. Group I consisted of a volunteer physician and 20 patients with dermatitis and four with psoriasis who formed part of another investigation. These subjects have been labelled as 'controls', for none had symptoms referable to the small intestine, all had normal faecal fat excretion, haemoglobin concentration, and d-xylose absorption, and their biopsy specimens were also histologically and histochemically normal. Seventeen children with coeliac disease constituted group II, while group III consisted of nine adults with idiopathic steatorrhoea. Group IV comprised 16 subjects who had had a gastric resection. Group V was a miscellaneous group of 10 children with acrodermatitis enteropathica (three); diarrhoea of undetermined cause (three); and one each with allergy of the alimentary tract to food (cow's milk, oranges, nuts, blackcurrants), pernicious anaemia, idiopathic hypoproteinaemia, and chronic intractable diarrhoea with hyperplasia of the islets of Langerhans. Among a miscellaneous group of 21 adults (group VI) there were 13 with diarrhoea of undetermined cause, two with pancreatic steatorrhoea, two with Crohn's disease, two with iron-deficiency anaemia with achlorhydria, one with pseudoxanthoma elasticum, and one with intestinal Hodgkin's disease.

In the subjects who had had a gastric resection the biopsy was taken from between 20 and $30 \mathrm{~cm}$. distal to the gastrointestinal anastomosis, and in the one patient with a total gastrectomy the specimen was obtained from the jejunum $12 \mathrm{~cm}$. below the diaphragm.

Estimations of faecal fat excretion, haemoglobin concentration, and d-xylose absorption were included among the laboratory tests carried out on most patients.

HISTOLOGY AND HISTOCHEMISTRY The biopsy specimen was divided into two or three pieces. One, fixed in ice-cold $80 \%$ alcohol, was photographed before processing to paraffin. Sections $7 \mu$ thick were stained with haematoxylin and eosin or with haematoxylin and van Gieson, by the P.A.S., Alcian blue or colloidal iron methods for mucopolysaccharides, and by the methyl green-pyronin technique for plasma cells.

A second piece of the biopsy was rapidly frozen in absolute alcohol- $-\mathrm{CO}_{2}$ mixture for sectioning in the cryostat at $-20^{\circ} \mathrm{C}$. The undermentioned techniques were used on frozen sections, accompanied always by control sections of normal rat intestine: the nitro-blue tetrazolium method for succinic dehydrogenase (Nachlas, Tsou, de Souza, Cheng, and Seligman, 1957) using an incubation period of 20 minutes; the method of Nachlas, Crawford, and Seligman (1957) for leucine aminopeptidase with an incubation period of 20 minutes (for some of the more recent specimens the method of Nachlas, Monis, Rosenblatt, and Seligman (1960) was used); the Gomori calcium-cobalt method for alkaline phosphatase (Pearse, 1960) with an incubation time of 15 minutes; the Gomori technique for acid phosphatase (Culling, 1957) with an incubation time of three hours; the $\alpha$-naphthyl acetate method for non-specific esterase (Pearse, 1960), with an incubation time of one minute; the oil red O method (Lillie, 1944) for fat; and the examination of wet sections after staining with $1 \%$ aqueous toluidine blue, to reveal metachromasia (Pearse, 1960).

STUDIES IN VITRO From some biopsy specimens a third fragment of tissue was used for an experiment in vitro. The tissue was placed in a roller tube containing $2 \mathrm{ml}$. of Glaxo culture medium no. 199 and maintained at $37^{\circ} \mathrm{C}$. for periods ranging from two to six hours. In some cases $2 \mu \mathrm{c}$. of tritiated thymidine was added to the medium. After fixation in alcohol, sections were prepared and stained by the methods already described for fixed biopsy material. From the specimens incubated with radioactive isotope, autoradiographs were prepared using the technique of Heatley, Jerrome, Jennings, and Florey (1956), with Kodak AR10 stripping film.

\section{RESULTS}

The specimens from the control group were considered to be histologically and histochemically within normal limits; some specimens contained fat and are described under the subheading 'presence of fat'.

MACROSCOPIC APPEARANCES The commonest gross appearance of the mucosa in specimens considered normal is illustrated in Fig. 1. Most of the villi are finger-like but they are admixed with a number that are more leafy in form. However, judging by the appearance of a number of other specimens from the control subjects which were subsequently found to be histologically and histochemically 


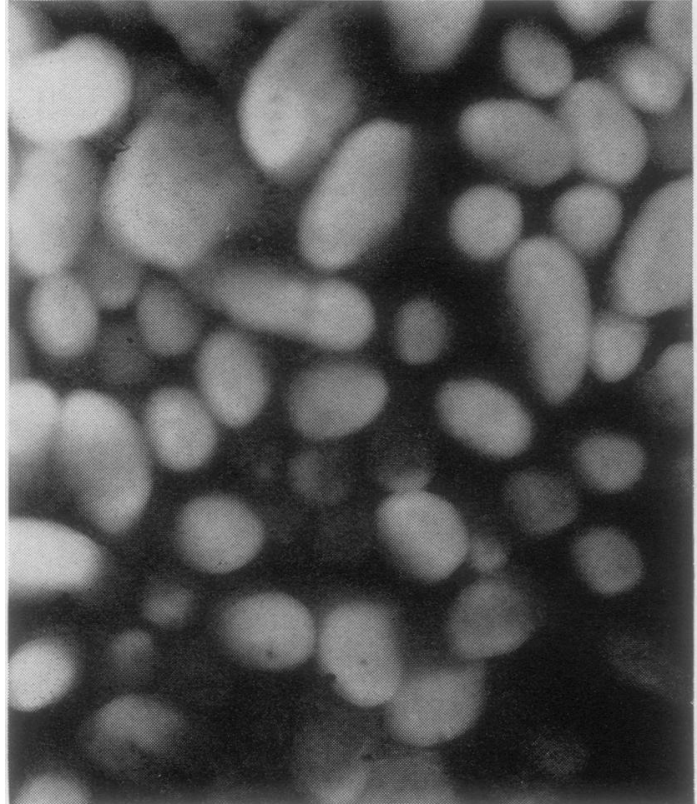

FIG. 1. Mucosa showing finger-like villi, with a few leafy forms. $\times 38$.

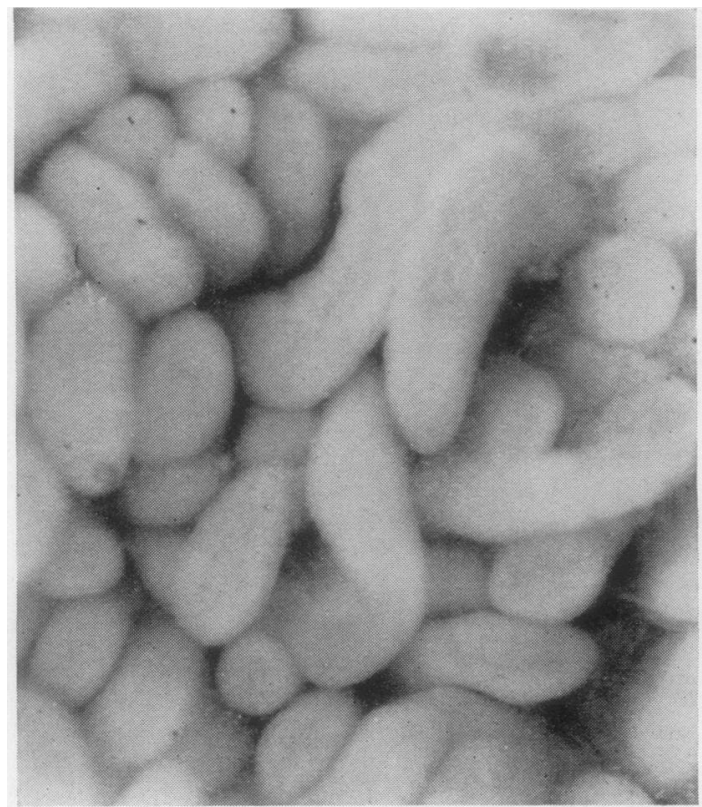

FIG. 2. Mucosa showing broad leaf-like villi, with relatively few finger-like forms. $\times 38$.

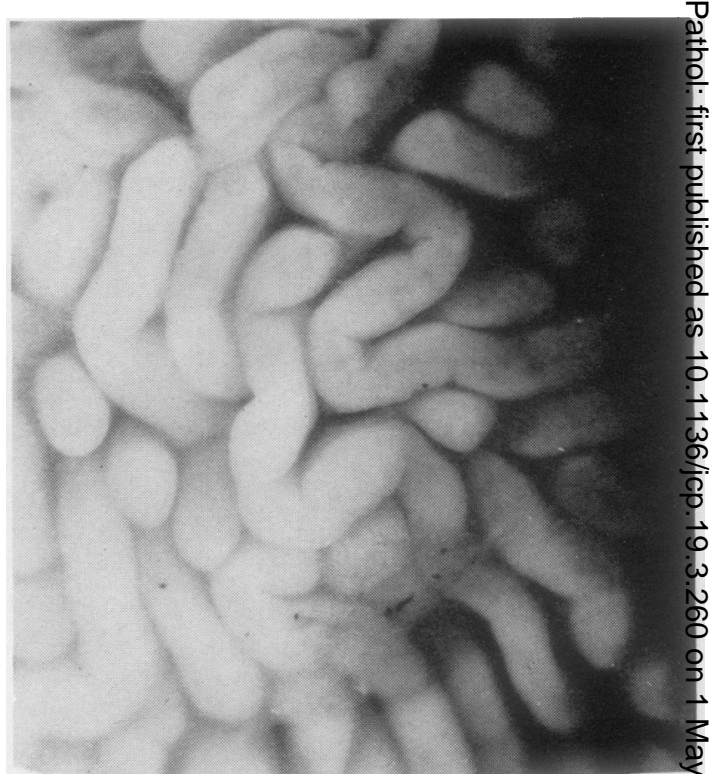

FIG. 3. Convoluted mucosa with only occasional fingers like villi. $\times 38$.

๙

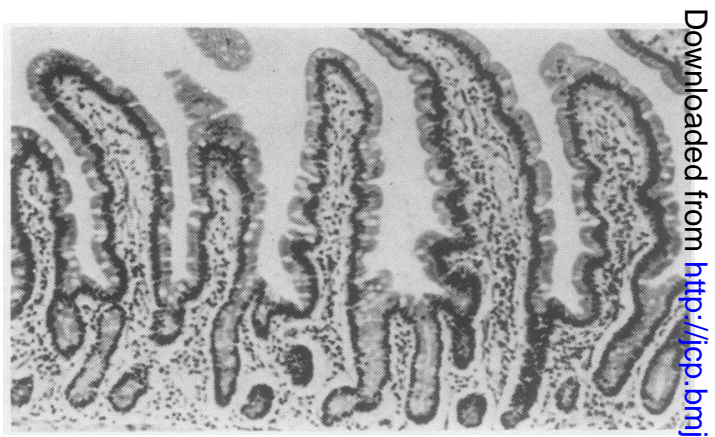

FIG. 4. Section of the specimen illustrated in Fig. Haematoxylin and eosin. $\times 30$.

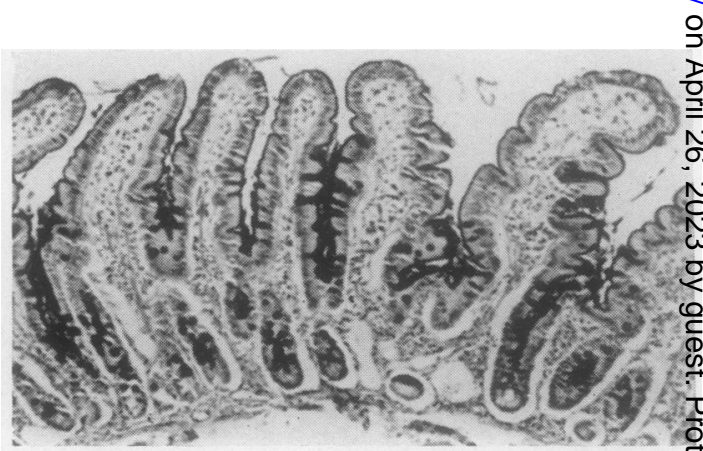

FIG. 5. Section of the specimen illustrated in Fig. Note the similarity with Fig. 4, although the gro 8 appearances of the two specimens are very differenf P.A.S. and haematoxylin. $\times 30$. 


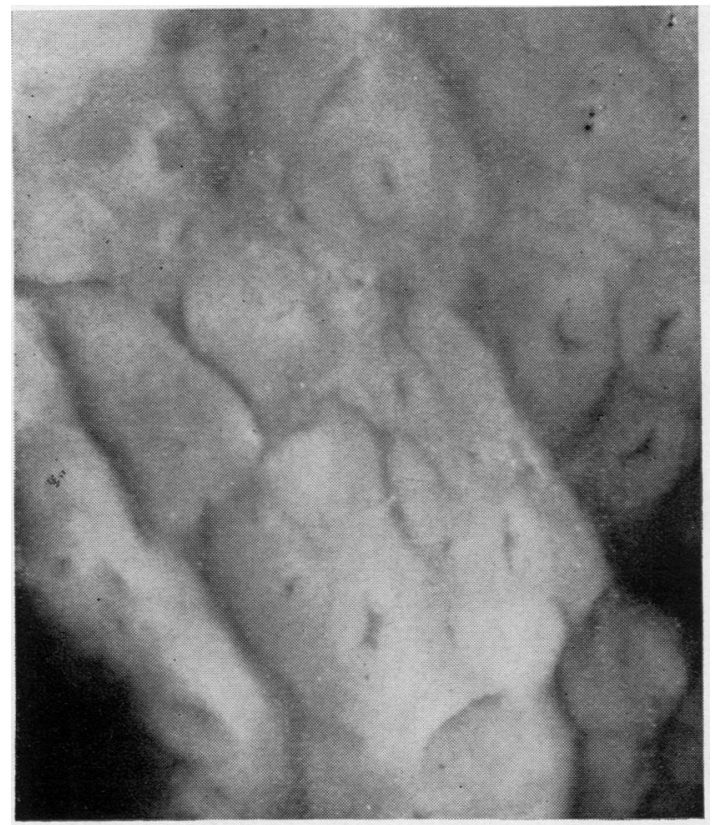

FIG. 6. Flat appearance of mucosa from a case of idiopathic steatorrhoea. Crypt mouths are readily visible on the surface. $\times 38$.

normal, there is considerable variation in what constitutes normality for this part of the alimentary tract. Sometimes a larger number of leaf-like villi are present (Fig. 2), and occasionally a specimen such as that illustrated in Fig. 3, where the mucosa is thrown into ridges and folds and is virtually indistinguishable from the convoluted pattern recorded below, must be considered within the limits of normality in view of the lack of any accompanying pathological process, as judged histologically, histochemically, and by clinical tests.

It must be noted that a true assessment of the gross appearance of the mucosa cannot necessarily be deduced from histological sections. Microscopically Figs. 4 and 5 are similar, and yet they were taken from the specimens in Figs. 1 and 3 which clearly are very different from each other.

Of the 17 biopsy specimens from the children with coeliac disease, eight specimens had a flat mucosa, two had a mosaic pattern, and nine were convoluted. In the idiopathic steatorrhoea group six of the nine specimens were flat (Fig. 6), one with mosaic pattern, and the remaining three were convoluted.

From the 16 subjects who had a gastric resection, eight specimens showed only finger-like villi, five had only leaf-like villi, two had a mixture of leaf- like and finger-like villi, and that from the patient who had a total gastrectomy was flat.

In the miscellaneous group of children, four specimens had a convoluted appearance and a diagnosis of coeliac disease was considered unlikely, while in the miscellaneous group of adults one specimen, that from a patient with intestinal Hodgkin's disease, was found to be flat.

CELlular INFILTRATION AND PLASMA Cells All the specimens from subjects with coeliac disease and idiopathic steatorrhoea showed infiltration with mononuclear cells. An excessive number of plasma cells was present in 13 of the 17 biopsies from the coeliac group and in seven of the nine specimens in the idiopathic steatorrhoea group.

Excessive infiltration was present in five of the 16 biopsies from subjects who had had a gastric resection, plasma cells predominating in two, one from a patient with a total gastrectomy, the other from a patient who also had a leiomyosarcoma of the duodenum. Among the child and adult groups with miscellaneous conditions, six infiltrated mucosae from children included all four convoluted specimens, while 11 of the 21 adult biopsies in group VI showed infiltration. However, none of the specimens in these two groups had an excess of plasma cells.

PRESENCE OF FAT In the control group, 10 of the 18 specimens stained for fat showed globules of lipid material, usually in localized areas of the connective tissue surrounding the bases of some of the crypts, in the form of small aggregations of globules that were probably extracellular, since cytoplasmic vacuoles that would have indicated intracellular fat were not found in the fixed fragment of the same biopsy. In one biopsy the fat was in the lamina propria of a few of the villi near their tips and in another it was in the submucosa only.

Of the 52 specimens examined from all the other groups fat was present in 25 . In general it was randomly distributed among the various groups and not related to any particular disease, but of four specimens in which it was found in significant quantity in epithelial cells, three were from children with coeliac disease.

METACHROMASIA Metachromatic staining of goblet cell mucin was detected in only four of 15 specimens from the coeliac and idiopathic steatorrhoea groups, whereas it was found in 17 of 18 specimens in groups IV, V, and VI, as well as in the control group.

INTRACELLULAR ENZYMES The results of the enzyme histochemistry tests in the mucosae of control 
subjects were in general agreement with the reports of Padykula et al. (1961), Dawson and Pryse-Davies (1963), and Spiro, Filipe, Stewart, Booth, and Pearse (1964) as far as their distribution in normal intestinal epithelium was concerned.

SUCCINIC DEHYDROGENASE There was a reduced reaction for this enzyme in all specimens from patients with coeliac disease and idiopathic steatorrhoea, and in the majority of these the reduction was gross in comparison with controls, especially in the surface epithelium of flat mucosae. In eight of the 16 specimens from the gastric resection group there was also some reduction and in four of these it was very marked. As in the specimens from groups II and III the reduction was greatest in the surface or villous type of epithelium. In group V there was a reduced reaction in seven of the 10 specimens and in group VI in 11 of the 21 specimens. In these groups the reduction was never as gross as was often seen in some cases of coeliac disease and idiopathic steatorrhoea.

ALKALINE PHOSPHATASE The staining reaction for alkaline phosphatase was not considered to be significantly reduced in any of the specimens examined, but because of the reduction of surface area in the flat and convoluted specimens there must have been a corresponding decrease in the total area of epithelium containing this enzyme.

ACID PHOSPHATASE Acid phosphatase was reduced or patchy in distribution in five of the 12 specimens examined from subjects with coeliac disease, but in four of the five specimens from patients with idiopathic steatorrhoea. No significant reductions were noted in other groups.

NON-SPECIFIC ESTERASE This enzyme was reduced in three of 13 coeliac specimens but in all six biopsies examined from patients with idiopathic steatorrhoea. Isolated specimens from other groups showed some reduction.

LEUCINE AMINOPEPTIDASE There were examples of reduced activity in all groups of patients; it was uniformly low in the idiopathic steatorrhoea group, and also in the children with coeliac disease, although in two of these a strong normal reaction was obtained.

STUDIES IN VITRO The object of culturing fragments of mucosa was to ascertain whether the tissues would survive in a culture medium sufficiently well to enable autoradiographic studies to be carried out on the epithelial cells. The mucosa was classified as 'preserved' when the epithelium of both crypts and villi (or surface cells in the case of fiat mucosa) was complete or virtually so, and 'degen' erate' when the villous or surface epithelium wefs totally destroyed.

Of 14 specimens of which the mucosa was macre scopically and histochemically normal, four showed good epithelial preservation after six hours $\mathbb{D}$ culture, the remainder being degenerate, but specimens from the coeliac and idiopathic steator rhoea groups all showed intact surface epithelium after similar culture periods. Autoradiographs made from material cultured with tritiated thymidie revealed some heavy uptake of isotope by a number of crypt cell nuclei, and also by some surface ceit nuclei in flat mucosae, but labelling was not uniform throughout the specimens, some crypts being devoid of any nuclear uptake.

\section{DISCUSSION}

Our findings support the concepts that a flat mucos: cannot be considered diagnostic of idiopathice steatorrhoea, and that a convoluted mucosa doos not necessarily indicate a pathological process. We fully endorse the remarks of Holmes et al. (196\$) concerning the need to examine specimens macroscopically in order to appreciate the true configure tion of the mucosa (cf. Figs. 1, 3, 4, and 5).

All the specimens from patients with coelia disease and idiopathic steatorrhoea showed $\vec{a}$ deficiency of succinic dehydrogenase in the epitheliā l cells, and the histochemical test for this enzyme may be a useful aid to diagnosis since the degree of deficiency noted was usually grosser in these disease states than in any other conditions. However, loy enzyme activity is not specific for these diseases since two other cases with flat mucosae (Hodgkin's disease and total gastrectomy) also showed gross deficiency. There was no correlation between a reduced reaction for succinic dehydrogenase and a deficiency of any of the other enzymes studied histochemically, nor was there any correlation between reduced enzynte activity and the severity or otherwise of the clinical features. With minor variations, our histochemicad findings are in broad agreement with those Padykula et al. (1961) and Spiro et al. (1964). It not possible to say how the enzyme defects may be manifesting themselves in terms of cell function; all that may be inferred is that cell metabolism has been altered in some way. As Spiro et al. have pointed out, the 'crucial enzyme defect' in the coeliac apd idiopathic steatorrhoea group of diseases has yet $\mathbb{1}^{\circ}$ be discovered.

In a number of specimens from a variety of other conditions in this series (diarrhoea of undetermined 
cause, or diseases suggesting abnormal intestinal function, such as acrodermatitis enteropathica, Crohn's disease, refractory iron-deficiency anaemia, or following partial gastric resection, occasional enzyme deficiences have been observed in mucosae that showed (normal) finger-like or leaf-like villi. In these instances the deficiencies were not as gross as those seen in coeliac disease or idiopathic steatorrhoea. It is possible that this represents an earlier stage of a 'damaged' mucosa than does an abnormal macroscopic appearance. If these apparent histochemical alterations can be confirmed biochemically, their histochemical demonstration may prove to be a useful indication of abnormal cell function in mucosae that would otherwise be considered normal on macroscopic or routine histological examination.

The intensity of the staining reaction for alkaline phosphatase was normal in all biopsies, and our experience suggests that the histochemical test for this enzyme indicates the extent of the villous type of epithelium in any given specimen. Cellular infiltration was common in many of the biopsies, but excess plasma cells were a frequent finding only in coeliac disease and idiopathic steatorrhoea.

It is not yet clear whether the presence of lipid material in the small intestinal mucosa of fasting subjects (Cameron et al., 1962; Samloff, Davis, and Schenk, 1965) is due to absorption before biopsy or to endogenous secretion. It was detected in 35 of 70 specimens in our series, not apparently related to any particular disease or group of patients, nor to the presence or absence of steatorrhoea.

There was a significant lack of goblet cell metachromasia in specimens from patients with coeliac disease and idiopathic steatorrhoea. The precise chemical basis for metachromatic staining is not yet understood, but the above results suggest some alteration in the composition of goblet cell mucin in these conditions.

From the specimens that have been maintained in a culture medium it appears that the epithelium of the flat or convoluted mucosae tend to undergo necrosis less quickly than that of the villous type. It is tempting to suggest that normal mucous membrane readily digests itself in vitro whereas the abnormal types are more resistant to autodigestion, possibly because of lower (unspecified) enzyme content. The autoradiographic results using medium containing tritiated thymidine indicated that penetration of the medium through the specimen was capricious, although some crypts did show large numbers of labelled cells. This approach is worthy of further study, for if reliable labelling could be obtained it would offer the opportunity of comparing epithelial turnover rates in normal and diseased mucosae without the need for injecting thymidine in vivo (cf. the work of Deschner, Lewis, and Lipkin, 1963 , on rectal biopsies).

We wish to thank all those physicians who allowed us to study patients under their care, in particular Dr. R. S. Bruce Pearson, Dr. P. Hugh-Jones, Sir Wilfred Sheldon, Dr. J. H. Baylis, and Professor C. D. Calnan. We are grateful to Messrs. P. Brinck and D. Farr for technical assistance, and to Mr. S. Hogwood for photography. L.F. was in receipt of a grant from King's College Hospital Research Fund for part of this project, and R.M.H.M. is in receipt of a grant from the Medical Research Council.

\section{REFERENCES}

Badenoch, J. (1960). Brit. med. J., 2, 879, 963.

Bank, S., Marks, I. N., Moshal, M. G., and Timme, A. (1964). S. Afr. med. J., 38, 451.

Booth, C. C., Stewart, J. S., Holmes, R., and Brackenbury, W. (1962). In Intestinal Biopsy (Ciba Foundation Study Group, no. 14), edited by G. E. W. Wolstenholme and M. P. Cameron, p. 2. Churchill, London.

Butterworth, C. E. Jr., and Perez-Santiago, E. (1958). Ann. intern. Med., 48, 8.

Cameron, A. H., Astley, R., Hallowell, M., Rawson, A. B., Miller, C. G., French, J. M., and Hubble, D. V. (1962). Quart. J. Med., $31,125$.

Cooke, W. T., Fone, D. J., Cox, E. V., Meynell, M. J., and Gaddie, R. (1963). Gut, 4, 279.

Creamer, B. (1964). Brit. med. J., 2, 1435.

Crosby, W. H., and Kugler, H. W. (1957). Amer. J. dig. Dis., 2, 236.

Culling, C. F. A. (1957). Handbook of Histopathological Technique (Including Museum Technique). Butterworth, London.

Dawson, I., and Pryse-Davies, J. (1963). Gastroenterology, 44, 745.

Deschner, E., Lewis, C. M., and Lipkin, M. (1963). J. clin. Invest., 42, 1922.

Doniach, I., and Shiner, M. (1960). Brit. J. Radiol., 33, 238.

Heatley, N. G., Jerrome, D. W., Jennings, M. A., and Florey, H. W. (1956). Quart. J. exp. Physiol., 41, 124.

Holmes, R., Hourihane, D. O'B., and Booth, C. C. (1961). Lancet, 1, 81.

Lillie, R. D. (1944). Stain Technol., 19, 55.

Nachlas, M. M., Crawford, D. T., and Seligman, A. M. (1957) J. Histochem. Cytochem., 5, 264.

Monis, B., Rosenblatt, D., and Seligman, A. M. (1960). J. biophys. biochem. Cytol., 7, 261.

- , Tsou, K. C., de Souza, E., Cheng, C. S., and Seligman, A. M (1957). J. Histochem. Cytochem., 5, 420.

Padykula, H. A. (1962). Fed. Proc., 21, 873.

-, Strauss, E. W. Ladman, A. J., and Gardner, F. H. (1961) Gastroenterology, 40, 735.

Pearse, A. G. E. (1960). Histochemistry, Theoretical and Applied, 2nd ed. Churchill, London.

Rubin, C. E., Brandborg, L. L., Phelps., P. C., and Taylor, H. C., Jr. (1960). Gastoenterology, 38, 28

Sakula, J., and Shiner, M. (1957). Lancet, 2, 876.

Salem, S. N., Truelove, S. C., and Richards, W. C. D. (1964). Brit. med. J., 1, 394.

Samloff, I. M., Davis, J. S. and Schenk, E. A. (1965). Gastroenterology, $48,155$.

Schiffer, L. M., Faloon, W. W., Chodos, R. B., and Lozner, E. L. (1962). Ibid, 42, 63.

Shiner, M. and Doniach, I. (1960). Ibid., 38, 419.

-, and Drury, R. A. B. (1962). Amer. J. dig. Dis., 7, 744.

Spiro, H. M., Filipe, M. I., Stewart, J. S., Booth, C. C., and Pearse, A. G. E. (1964). Gut, 5, 145.

Wangel, A. G., and Deller, D. J. (1965). Ibid., 6, 73. 